\title{
Optimization of total investment cost of solar distribution network
}

\author{
M.Siali ${ }^{1}$, S. Fergani ${ }^{1}$, S.Flazi $^{1}$, A. Boudghene Stambouli ${ }^{2}$ \\ ${ }^{1}$ Department of Electrical Engineering \\ Phone/Fax number: +00213 778428 023, e-mail: mokhtaria.siali@gmail.com, fergani.samia@ hotmail.fr, \\ flazis@yahoo.fr, \\ ${ }^{2}$ Department of electronic \\ E-mail aboudghenes@gmail.com, \\ University of Sciences and Technology of Oran -Mohamed Boudiaf- (USTO-MB-) \\ B.P 1505 EL M'NAOUER. ORAN. ALGERIA
}

\begin{abstract}
The position of the PV generator and the electrical cables sections influence the whole cost of installation during the operation life of a network. The aim of our work is to find the number of the solar generators, and the optimal location for installing them in order to optimize the total investment cost of a distribution network. In this paper, we will discuss the methods that we have developed to optimize this cost, and study the influence of cables cross sections, the number and the locations of the generators on the optimization. We have proposed three methods:

-The gravity center method to optimize the volume of copper taking into account only the voltage drop sections.

-The method of the minimum copper volume center, to optimize the same cost but taking into account all the technical sections and the economic sections.

-The method of the minimum cost center to optimize the overall investment cost using the optimal sections. After that, we have studied the influence of the number of the generators on the optimization using the method of minimum cost center. The use of MATLAB software has helped us to verify and confirm our results.
\end{abstract}

\section{Key words}

Optimization, distribution network, total investment cost, solar generator, optimal sections.

\section{Introduction}

The distribution networks may be susceptible to transmission losses by virtue of their low voltages even over distances of a few hundred feet. If cables are not sized properly, distribution losses can tax limited generation capacities and create voltage drops at the end user level that will prevent equipment from operating. [1] So, we need to optimize the technical cables sections which satisfy the three conditions: [2]

- Drop voltage

- Normal heating

- Overload due to a short-circuit
On the other hand, these sections must allow minimizing the electric losses in the cables. And in order to make a PV power generation system survive as an economically viable option against other renewable energy sources, drastic reduction of energy cost is inevitable. [3]

The objective of this work is to optimize the total investment cost of a distribution network supplied by a solar source. It is therefore very important to determine the sections and lengths of cables, the number of generators and their positions; and study the influence of them on the optimization of investment cost. We have proposed three methods of calculation to find the position of the generator; the first method which is the gravity center method is widely used in the optimization of distribution network [4,5], but it does not take into account several parameters that have an important influence on the choice of the generator position. For this, we have developed two other methods to find the optimal position of the generator. These two methods can be used not only in the optimization of network supplied by a solar source but also to optimize the conventional networks. The three methods are:

- The gravity center method for optimizing the volume of copper, and therefore the investment cost of cables, using only the voltage drop sections.

- The center of the minimum volume of copper, this method optimizes the volume of copper used in the cables taking into account all the technical sections and the economic sections.

- The method of the minimum cost center, it is based on the optimization of the total investment cost of network using the optimal sections.

To take all the possible positions of the solar generator, a variation of its position starting from a point $\mathrm{O}\left(\mathrm{x}_{0}=0\right.$, $\mathrm{y}_{0}=0$ ) by making a sweeping on the entire surface where are the loads, is required; in order to study its influence on the calculation and find the optimal position. 


\section{The optimal section}

The optimal section is the greatest between the economic section and the technical section.

\section{A. The economic section}

The economic section of the cables on a line is that which carries out the best compromise between the cost of these cables and the cost of the losses that will generator over all their operation life. [6]

\section{The calculation method}

The economic section is a section for which the total investment cost is minimum.

The total cost of a distribution network is the sum of the total cost of the annual amortization of the purchase price of the cables and the amount of the annual losses of energy, it has as an expression: [2]

$$
C_{t}=\sum_{i}^{n}\left(A\left(f+G \cdot S_{i}\right) l_{i} \cdot 10^{3}+\text { n.e. } \rho \cdot \frac{l_{i} \cdot I_{i}^{2}}{. S_{i}} \cdot H 10^{-3}\right)
$$

$C_{t}$. the total cost. (DA)

e. Electrical energy price. (DA/kWh)

$\mathrm{S}_{\mathrm{i}}$. Section of $\mathrm{i}^{\text {th }}$ cable. $\left(\mathrm{mm}^{2}\right)$

G. f. constant.

A. Annual amortization of the purchase price of the cable.

$\mathrm{I}_{\mathrm{i}}$. Intensity to be transported in the $\mathrm{i}^{\text {th }}$ cable. (A)

$l_{i}$. Length of the $\mathrm{i}^{\text {th }}$ cable. $(\mathrm{km})$

$\mathrm{H}$. Number of service hours of connection per day.

$\mathrm{n}$. Active conductors number of the connection

$\rho$. Resistivity of the conductive metal at the service temperature, $\Omega \mathrm{mm}^{2} / \mathrm{Km}$.

For a solar distribution network, the total cost is different than the conventional network, because the amount of the annual losses of energy is not the same; and it is given by the following formula:

$$
\begin{gathered}
\mathcal{C}_{\text {los }}=\sum_{i}^{n}\left(n \cdot B \cdot \rho \cdot A_{g} \frac{l_{i} \cdot I_{i}{ }^{2}}{h_{e} \cdot S_{i}} \cdot H 10^{-3}\right) \\
B=\frac{P_{g 2}-P_{g 1}}{p_{r 2}-p_{r 1}}
\end{gathered}
$$

In this case the total cost of a solar distribution network is calculated by the following equation:

$$
c_{t}=\sum_{i}^{n}\left(A\left(f+G \cdot S_{i}\right) l_{i} \cdot 10^{3}+n B \cdot \rho \cdot A_{g} \frac{l_{i} \cdot I_{i}{ }^{2}}{h_{e} \cdot S_{i}} H 10^{-3}\right)
$$

It is minimum for the economic section $\left(\mathrm{S}_{\mathrm{ei}}\right)$ such as:

$$
S_{e i}=I_{i} \sqrt{\frac{n \cdot B \cdot \rho \cdot A_{g} \cdot H \cdot 10^{-3}}{h_{e} \cdot G \cdot A \cdot 10^{3}}}
$$

Where:

$C_{l o s}$. The amount of the annual losses of energy of salar source. (DA)

$\mathrm{S}_{\mathrm{ei}}$. Economic section of the $\mathrm{i}^{\text {th }}$ cable. $\left(\mathrm{mm}^{2}\right)$

$B$. constant.

$P_{g}$. The fixed price of a solar generator.

$P_{r}$. Power required by the generator according to the losses. (kW).

$A_{g}$. Annual amortization of the purchase price of the solar generator.

$h_{e}$. Represent the daily number of sunshine hours.

\section{B. The technical section}

To find the technical section of each cable, we must retain the greatest section between the three following sections:

- Drop voltage section.

- Normal heating section.

- Section of overload due to a short-circuit.

And we seek the corresponding standardized section. [2]

\section{1) Drop voltage section}

For a maximum voltage drop authorized, the cross section of each cable connected to the solar generator is given by the following equation: [7]

$$
S_{i}=\frac{\sqrt{3}}{\Delta u} \cdot \rho \cdot \cos \phi \cdot I_{i} \cdot l_{i}
$$

$\Delta u$. authorized voltage drop.

$$
l_{i}=\left(\left(x_{i}-x_{G}\right)^{2}+\left(y_{i}-y_{G}\right)^{2}\right)^{1 / 2}
$$

$\left(x_{i}, y_{i}\right)$. Cartesian coordinates of the $\mathrm{i}^{\text {th }}$ load.

$\left(x_{G}, y_{G}\right)$. Cartesian coordinates of the solar generator.

2) Normal heating section: [2]

The temperature of the cable heart under normal functioning and permanent should not exceed the acceptable maximum temperature by the constituting materials of the cable selected. This condition determines the permanent section $S_{\mathrm{p}}$.

We must calculate the reference current to find the $S_{p}$ section:

$$
I_{\text {ref }}=\frac{I_{i}}{k}
$$

$\mathrm{k}$. the product of various correction factors.

3) Section of overload due to a short-circuit [8]

The heating corresponding to the intensities of overload carries, during a very short time, the insulator of the cable to a higher temperature than which allowed under normal functioning.

For the calculation of short-circuit section $S_{c}$, we can use the following equations:

$$
\begin{gathered}
S_{c i}=\frac{I_{c i}}{\delta_{i}} \\
\delta_{i}=\frac{\delta_{0}}{\sqrt{t}}
\end{gathered}
$$


$S_{c i}$. Section of overload due to a short-circuit of the $\mathrm{i}^{\text {th }}$ cable. $\left(\mathrm{mm}^{2}\right)$

$I_{c i}$. Short courant circuit on the $\mathrm{i}^{\text {th }}$ cable. (A)

$\delta_{i}$. Admissible current density. $\left(\mathrm{A} / \mathrm{mm}^{2}\right)$

$\delta_{0}$. Current density allowable short circuit during 1 second. $\left(\mathrm{A} / \mathrm{mm}^{2}\right)$.

$t$. the short-circuit duration. (s)

\section{Optimal location}

To find the optimal location to install the solar generator, in order to optimize the investment cost, we propose three methods.

\section{A. gravity center method [9]}

The method used is comparable to the determination of the gravity center of a system made up of points weighted with the power ratings of a various electrical loads.

The Cartesian coordinates of gravity center are calculated by the following formulas:

$$
\begin{aligned}
& x_{G C}= \frac{\sum_{i}^{n} x_{i} \cdot p_{i}}{\sum_{i}^{n} p_{i}} \\
& y_{G C}=\frac{\sum_{i}^{n} y_{i} \cdot p_{i}}{\sum_{i}^{n} p_{i}}
\end{aligned}
$$

$p_{i}$. Pwer of the $\mathrm{i}^{\text {th }}$ load. $(\mathrm{W})$.

$\left(x_{i}, y i\right)$. The cartesian coordinates of the $\mathrm{i}^{\text {th }}$ load. $(\mathrm{km}, \mathrm{km})$

Using Matlab programming, for each position of the generator, we have calculated the length of each cable, its drop voltage section and the volume of copper using the following formula:

$$
V=\sum_{i}^{n} S_{i} \cdot l_{i}
$$

We have found that the smallest volume is at the gravity center.

So, in order to optimize the cost of investment of cable for a mínimum volume of copper and taking into account an authorized voltage drop, the gravity center is the optimal location to install the solar generator.

\section{B. The center of the minimum volume of copper [10]}

For each position of the generator, we have calculated the technical section of each cable and its length to be able to recalculate the volume of copper and the investment cost of cables; using the formula (10) and the following formulas:

$$
\begin{gathered}
C_{c i}=A\left(k+G . S_{i}\right) l_{i} \\
C_{t c}=\sum_{i}^{n} C_{c i}
\end{gathered}
$$

$\mathrm{C}_{\mathrm{t}}$ : the total cost of the annual amortization of the purchase price of the cable. (DA)

The obtained results showed that the optimal center does not correspond to the gravity center.

Therefore, the optimal generator location that allows minimizing the cost of investment of cables taking into account the technical sections is in the minimum volume center.

\section{The method of the minimum cost center}

The previous method optimizes the investment cost of cables, and our objective is to optimize the overall investment cost of the network. For this, we proposed the method of the minimum cost center. This method generalizes the other methods.

In each position of the generator, we calculated all the technical sections, the economic sections and the optimal sections. Using these sections, we calculated the volume of copper, the investment cost of the cables and the total network investment cost (using the formula (1)). And we have looked for the positions of the minimum of these three values. We found that the positions are different.

The optimal location of the solar generator is in the position that allows us to optimize the overall investment cost of the network; we call it the minimum cost center.

From the examples that we have treated, we found that sometimes, the center of the minimum volume of copper and the minimum cost center have the same coordinates (same position gives us the minimum of investment cost of cables and the minimum of the total network investment cost).

\section{Examples}

Among the examples treated, we propose two examples:

\begin{tabular}{|c|c|c|c|c|}
\hline $\begin{array}{l}\text { Loads } \\
\mathrm{p}(\mathrm{W})\end{array}$ & $\begin{array}{c}\mathrm{X} \\
(\mathrm{km})\end{array}$ & $\begin{array}{c}\mathrm{Y} \\
(\mathrm{km})\end{array}$ & $\begin{array}{c}\text { Minimum } \\
\text { volume } \\
\text { center } \\
\mathrm{X}(\mathrm{km}), \mathrm{Y}(\mathrm{km}) \\
\end{array}$ & $\begin{array}{c}\text { Minimum } \\
\text { cost center } \\
\mathrm{X}(\mathrm{km}), \mathrm{Y}(\mathrm{km})\end{array}$ \\
\hline 30000 & 0.69 & 0.147 & \multirow{6}{*}{$\begin{array}{l}X=0.47 \\
Y=0.50\end{array}$} & \multirow{6}{*}{$\begin{array}{l}X=0.50 \\
Y=0.39\end{array}$} \\
\hline 35000 & 0.465 & 0.36 & & \\
\hline 15000 & 0.85 & 0.05 & & \\
\hline 20000 & 0.36 & 0.721 & & \\
\hline 19500 & 0.047 & 0.84 & & \\
\hline 16500 & 0.521 & 0.96 & & \\
\hline
\end{tabular}
The first one, a site of six loads, where we have found that the center of the minimum volume of copper and the minimum cost center do not have the same coordinates.

Table I. - Example of 6 Loads 
The second example, a site of five loads, where the center of the minimum volume of copper and the minimum cost center have the same coordinates.

Table II. - Example of 5 Loads

\begin{tabular}{|c|c|c|c|c|}
\hline $\begin{array}{c}\text { Loads } \\
\mathrm{p}(\mathrm{W})\end{array}$ & $\begin{array}{c}\mathrm{X} \\
(\mathrm{km})\end{array}$ & $\begin{array}{c}\mathrm{Y} \\
(\mathrm{km})\end{array}$ & $\begin{array}{c}\text { Minimum } \\
\text { volume center } \\
\mathrm{X}(\mathrm{km}), \mathrm{Y}(\mathrm{km})\end{array}$ & $\begin{array}{c}\text { Minimum cost } \\
\text { center } \\
\mathrm{X}(\mathrm{km}), \mathrm{Y}(\mathrm{km})\end{array}$ \\
\hline 32000 & 0.055 & 0.55 & & \\
\cline { 1 - 3 } 37000 & 0.505 & 0.055 & $\mathrm{X}=0.32$ & $\mathrm{X}=0.32$ \\
\cline { 1 - 2 } 18000 & 0.505 & 0.505 & \multirow{2}{*}{$\mathrm{Y}=0.30$} & $\mathrm{Y}=0.30$ \\
\cline { 1 - 2 } 24000 & 0.305 & 0.285 & & \\
\cline { 1 - 2 } 25000 & 0.255 & 0.195 & & \\
\hline
\end{tabular}

\section{Optimization of the solar generator number}

For a generator placed in the minimum cost center, the total cost of investment is optimized. How can we minimize this cost, using several generators?

For a group of (n) loads, Using Matlab programming, we seek all possible combinations of loads.

We must find the minimum total investment cost of each group of the combination using the method of the minimum cost center; after having determined the minimum cost of each one, we calculate the sum to find the total cost of the combination. And we seek the combination that gives us a minimum total investment cost.

The number of groups in the optimal combination corresponds to the number of the generators used. (For each group, we use a generator).

For one combination, the total cost is calculated with the following formula:

$$
\begin{gathered}
C_{t g}=C_{t}+k_{e} \cdot B \cdot A_{g} \cdot \sum_{i}^{n} p_{i} \\
C_{t c b}=\sum_{i}^{m} C_{t g}
\end{gathered}
$$

Where:

$\mathrm{C}_{\mathrm{tcb}}$ : the total investment cost of a combination. (DA)

$\mathrm{C}_{\mathrm{tg}}$ : the total investment of group. (DA)

$\mathrm{k}_{\mathrm{e}}$ : simultaneity coefficient.

$\mathrm{P}_{\mathrm{i}}$ : power loads $(\mathrm{kW})$

\section{Example}

Among the examples treated, we propose an example of eleven loads, where we have found that the use of two generators is more economic than the use of one generator.

\begin{tabular}{|c|c|c|c|c|}
\hline $\begin{array}{l}\text { Loads p } \\
\text { (W) }\end{array}$ & $\begin{array}{c}\mathrm{X} \\
(\mathrm{km})\end{array}$ & $\begin{array}{c}\mathrm{Y} \\
(\mathrm{km})\end{array}$ & $\begin{array}{c}\text { The total } \\
\text { investment cost } \\
\text { (DA) }\end{array}$ & $\begin{array}{c}\text { Minimum } \\
\text { cost center } \\
\mathrm{X}(\mathrm{km}) \\
\mathrm{Y}(\mathrm{km})\end{array}$ \\
\hline $\begin{array}{c}\mathrm{C} 1 \\
(42400)\end{array}$ & 0.05 & 0.05 & \multirow{11}{*}{$\begin{array}{c}9679988.40933 \\
3915\end{array}$} & \multirow{11}{*}{$\begin{array}{r}X=0.38 \\
Y=0.475\end{array}$} \\
\hline $\begin{array}{c}C 2 \\
(44000)\end{array}$ & 0.2 & 0.1 & & \\
\hline $\begin{array}{c}\mathrm{C} 3 \\
(40000)\end{array}$ & 0.01 & 0.2 & & \\
\hline $\begin{array}{c}\mathrm{C} 4 \\
(33000)\end{array}$ & 0.6 & 0.7 & & \\
\hline $\begin{array}{c}\mathrm{C5} \\
(37500)\end{array}$ & 0.75 & 0.9 & & \\
\hline $\begin{array}{c}\text { C6 } \\
(35000)\end{array}$ & 0.75 & 0.7 & & \\
\hline $\begin{array}{c}\mathrm{C} 7 \\
(45000)\end{array}$ & 0.62 & 0.89 & & \\
\hline $\begin{array}{c}\mathrm{C} 8 \\
(53000)\end{array}$ & 0.67 & 0.5 & & \\
\hline $\begin{array}{c}\text { C9 } \\
(18000)\end{array}$ & 0.19 & 0.31 & & \\
\hline $\begin{array}{c}\mathrm{C} 10 \\
(26000)\end{array}$ & 0.05 & 0.4 & & \\
\hline $\begin{array}{c}\mathrm{C} 11 \\
(34000)\end{array}$ & 0.15 & 0.5 & & \\
\hline
\end{tabular}

Table III. - Example of 11 loads using 1 generator.

Using the method of the minimum cost center and Matlab programming, we have found the optimal combination of loads that has allowed us to minimize the total cost of investment. This combination is composed of two groups. Therefore, the solar generator number is determined.

\begin{tabular}{|c|c|c|}
\hline Groups & $\begin{array}{c}\text { The total investment } \\
\text { cost (DA) }\end{array}$ & $\begin{array}{c}\text { Minimum } \\
\text { cost center } \\
\mathrm{X}(\mathrm{km}), \mathrm{Y}(\mathrm{km})\end{array}$ \\
\hline $\begin{array}{c}\text { The } 1^{\text {st }} \text { group } \\
(\mathrm{C} 1, \mathrm{C} 2, \mathrm{C} 3, \mathrm{C} 9, \\
\mathrm{C} 10, \mathrm{C} 11),\end{array}$ & $\begin{array}{c}\mathrm{C}_{\mathrm{tg} 1}= \\
2924752.567275511\end{array}$ & $\begin{array}{c}X=0.12 \\
Y=0.225\end{array}$ \\
\hline \multirow[t]{2}{*}{$\begin{array}{c}\text { The } 2^{\text {nd }} \text { group } \\
(\mathrm{C} 4, \mathrm{C} 5, \mathrm{C} 6, \mathrm{C} 7, \\
\mathrm{C} 8)\end{array}$} & $\begin{array}{c}\mathrm{C}_{\mathrm{tg} 2}= \\
2861413.115911210\end{array}$ & $\begin{array}{c}X=0.685 \\
Y=0.73\end{array}$ \\
\hline & $\begin{array}{c}\mathrm{C}_{\mathrm{tcb}}= \\
5786165.683186721\end{array}$ & \\
\hline
\end{tabular}

Table IV. - Example of 11 loads using 2 generators.

It could be seen that a reduction of $40.22 \%$ on the cost can be gained if we use two generators.

\section{Conclusion}

- The gravity center method allowed us to optimize the volume of copper used in the cables and thus the investment cost of cables, taking into account an authorized voltage drop but several parameters are not considered in this method. For this we have developed two others methods. The first one is the center of the 
minimum volume of copper, it takes into account all the technical sections and allowed optimizing the investment cost of cables. This method is reliable in the case where the minimum cost center is the same as the center of the minimum volume. (The position of the minimum volume of copper allows minimizing the total investment cost of network). But this case is not always true.

- The second method which is the method of the minimum cost center is the best method to find the location of the solar generator that allows optimizing the total investment cost of a solar distribution network taking into account the optimal sections.

- The optimization of the number of the solar generators is very important in the optimization of the total cost of investment. If the loads are spaced from long distances, the use of several generators is required. If the loads are not remote from each other, one generator is sufficient.

The reduction in the cost of PV system allows to the solar energy to be an economically viable option compared to other energy sources.

\section{References}

[1] Matthew, J. Scully and Yeul Park, "Cable Network Analysis for Low Voltage Power Distribution systems", 978-1-46732308-6/12/\$31.00 @2012 IEEE 2.

[2] guide "cable et files électriques-apparellage" tréfimétaux 14 Edition-1977, imprimé en janvier 1977 par IPV.91700.Ste Geneviève des bois.

[3] Kimitoshi Fukae, Akiharu Takabayashi, Shigenori Itoyama, Ichiro Kataoka, Hidehisa Makita, Masaaki Matsushita, Takaaki Mukai and Nobuyoshi Taehara, " Proposal of unique PV system for Large-Scale Photovoltaic Power Generation system", $3^{\text {rd }}$ World conference on photovoltaic Enera Conversion May 11-18. 2003 Osaka, Japan. PP 2815-2820.

[4] Hubert Malwé Boudoué, Noël Djongyang, Serges Yamigno Doka, Yuenyuené Njoya Mohamed Moutala, Gambo Betchéwé, Timoléon Crépin Kofané « Reducing electrical energy losses in photovoltaic source distribution networks ». International Journal of Basic and Applied Science, 3(3) 2014. 257-262.

[5] R. Tchuidjan, O. Hamandjoda et M. Tabe, "'Réduction des pertes de puissance dans un réseau de distribution alimenté par un générateur d'énergie nouvelle et renouvelable", Revue des Energies Renouvelables, 2011, Vol. 14, N³, $449-459$.

[6] Henri Persoz, Jean-Claude Lemoine, Paul Sapet and Gérard Santucci, preface de Claude Bienvenu, " la planification des réseaux électriques”, Edition EYROLLES 1984.ISSN 03994198.

[7] Ouvrage réalisé par un groupe animé par Gérard SOLIGNAC, «guide de l'ingénierie électrique des réseaux internes d'usines », ISBN 2-85206-311-5, deuxième tirage revu. Juin 1986. ch.9. pp19.

[8] catalogue générale 1990, «cables isolés et matériels de raccordement énergie-télécommunications ».

[9] M.SI ALI, S. Fergani, S. Flazi and a. Boudghene Stambouli, "Optimization of copper in renewable source based network", International Conference on Renewable Energies and Power Quality (ICREPQ'14). Cordoba (Spain). $8^{\text {th }}-10^{\text {th }}$ April, 2014. ISSN 2172-038 X, No.12, April 2014

[10] M.SI ALI, S. Fergani, S. Flazi and A. Boudghene Stambouli "Optimazation of renewable distribution network", Grand Renewable Energy 2014, International Conference and Exhibition. July $27^{\text {th }}$ - August $1^{\text {st }}, 2014$. Tokyo Big Sight, Tokyo, Japan 